\title{
LABORATÓRIO GRUPO DE EXPERIMENTAÇÃO EM ARTEFATOS 3D: experiências de ENSINO, PESQUISA E EXTENSÃO
}

\author{
GRUPO DE EXPERIMENTAÇÃO EM \\ ARTEFATOS 3D LABORATORY: TEACHING, \\ RESEARCH AND EXTENSION EXPERIENCE
}

\author{
Leticia Teixeira Mendes \\ Doutora em Arquitetura, \\ Tecnologia e Cidade \\ Docente do Departamento de \\ Expressão Gráfica, \\ Universidade Federal de \\ Pernambuco, Recife, Brasil \\ leticia.mendes@ufpe.br
}

\section{Auta Luciana Laurentino \\ Doutora em Design Docente do Departamento de Expressão Gráfica, Universidade Federal de Pernambuco, Recife, Brasil auta.laurentino@ufpe.br}

\section{Sadi da Silva Seabra Filho}

Mestre em Design Docente do Departamento de Expressão Gráfica, Universidade Federal de Pernambuco, Recife, Brasil sadi.seabrafo@ufpe.br

\section{Pedro Martins Alessio}

Doutor em Interfaces Digitais para ambientes 3D

Docente do Departamento de Expressão Gráfica,

Universidade Federal de Pernambuco, Recife, Brasil pedro.alessio@ufpe.br

\section{RESUMO}

Frente ao crescimento significativo de temas que envolvem as tecnologias digitais nos currículos de cursos de graduação e pós graduação, bem como seu potencial de mercado, entende-se ser necessário que o ambiente acadêmico esteja preparado para responder ao desafio de ampliar e consolidar experiências didáticas e capacitação de pessoas por meio da implantação de um laboratório de prototipagem e fabricação digital. Dentro desse contexto, o presente artigo pretende apresentar e discutir ações/atuações do Laboratório do Grupo de Experimentação em Artefatos 3D, após a implementação do seu espaço físico junto ao Departamento de Expressão Gráfica, da Universidade Federal de Pernambuco. As atividades apresentadas demonstram o potencial da introdução das tecnologias digitais, nas áreas de ensino, pesquisa e extensão, e sua contribuição para a melhoria das atividades acadêmicas por meio do uso de novas abordagens integrando os conhecimentos das áreas da geometria gráfica, arquitetura e engenharia. A metodologia proposta baseia-se no método da pesquisa-ação e na prática reflexiva. Acreditamos que essa mediação do emprego das tecnologias no ensino, na pesquisa e na extensão, expostos nos casos apresentados neste trabalho, vem demonstrando resultados que confirmam o compromisso de uma educação voltada para a sociedade.

Palavras-chave: tecnologias digitais; prototipagem rápida; ensino; pesquisa; extensão

\section{ABSTRACT}

The significant growth of digital technologies topics in undergraduate and postgraduate curricula, as well as their market potential make necessary to the academic environment to respond to the challenge of expanding and consolidating didactic experiences and personal training by the implementation of a prototyping and digital manufacturing laboratory. Within this context, this article intends to present and discuss the actions and actuations of the Grupo de Experimentação em Artefatos 3D Laboratory developed after its physical space implementation in the Department of Graphic expression of the Federal University of Pernambuco. The activities presented demonstrate the potential of the introduction of digital technologies in the areas of teaching, research and extension and its contribution to the improvement of academic activities through the use of new approaches integrating knowledge in the areas of graphic geometry, architecture and engineering. The proposed methodology is based on the research-action method and reflective practice. We believe that this mediation of the use of technologies in teaching, research and extension, exposed in cases presented in this work, has been demonstrating results that confirm the commitment of an education oriented to society.

Keywords: digital technologies; rapid prototyping; teaching; search; extension 


\section{INTRODUÇÃo}

A introdução de tecnologias digitais nas áreas de projeto se deve, em grande parte, ao rápido desenvolvimento da indústria da computação. Esse novo paradigma tem criado ferramentas e possibilidades criativas na rotina de diversos profissionais como artistas, arquitetos, designers e engenheiros. Recentemente, a partir da inserção das ferramentas de prototipagem rápida e fabricação digital, tornou-se possível utilizar modelos geométricos digitais diretamente na produção de objetos à componentes em escala real.

Após a introdução da tecnologia digital no mundo acadêmico, a investigação das potencialidades dessas ferramentas na prática projetual, muitas vezes, alcançou posições radicais. Ortega (2009) aponta três grupos de posicionamento relacionados a esse fenômeno: o primeiro, caracterizado por uma confiança excessiva na tecnologia e em sua capacidade de converter-se em uma tábua salva-vidas ante um cenário pós-modernista rampante; o segundo grupo reagiu com grande indiferença ante a aparição do computador, aceitando-o no máximo como uma "prótese" para o projetista; e o terceiro grupo é formado por uma geração de profissionais que não problematiza o digital, pois seus interesses são diversos, múltiplos e plurais, incorporando facilmente as ferramentas digitais à prática projetual, em uma espécie de pragmatismo não declarado.

Frente ao crescimento significativo de temas que envolvem as tecnologias digitais nos currículos de cursos de graduação e pós graduação (PUPO e CELANI, 2008; PUPO e CELANI, 2011 e PUPO et al., 2011), bem como seu potencial de mercado, entende-se que é necessário que o ambiente acadêmico esteja preparado para responder ao desafio de ampliar e consolidar experiências didáticas e capacitação de pessoas por meio da implantação de um laboratório de prototipagem rápida (PR) e fabricação digital (FD).

O Departamento de Expressão Gráfica da Universidade Federal de Pernambuco (UFPE) é responsável por disciplinas que contemplam saberes da Geometria Gráfica e diferentes abordagens para representar graficamente um projeto. É responsável, portanto, por diversos componentes presentes nos currículos de graduação dos cursos de Arquitetura e Urbanismo, Engenharias e Licenciatura em Expressão Gráfica. Dessa forma, o presente artigo objetiva apresentar as estratégias e ações do laboratório de prototipagem rápida do Grupo de Experimentação em Artefatos 3D (GREA3D), cuja produção busca intercalar experiências nas áreas de ensino, pesquisa e extensão universitária.

As atividades desenvolvidas no laboratório estão voltadas a graduação, com o objetivo de promover melhorias e atualizações no currículo do curso, ao passo que busca possibilitar o uso de ferramentas digitais e conhecimentos durante a formação acadêmica, contribuindo na atuação profissional dos discentes de maneira efetiva e de acordo com as exigências atuais do mercado.

\section{METODOLOGIA}

A metodologia proposta nos estudos de caso apresentados no presente artigo baseiase no método da pesquisa-ação, proposto por Kurt Lewin, nos anos 1940 e na prática reflexiva, definida por Schön, em 1983. Segundo Tripp (2005), este método se insere no processo básico de investigação-ação; dentre eles estão a pesquisa-ação (1946) e a prática reflexiva (1983), entre outros. 
Este método tem como objetivo propor uma teoria do conhecimento que partisse da competência e do talento já inerentes à prática habilidosa - em um exercício definido como reflexão-na-ação, ou seja, o "pensar o que fazem, enquanto o fazem" (SCHÖN, 1983; SCHÖN, 2000):

Quando um profissional vê uma situação nova como um elemento de seu repertório, ele tem uma maneira nova de ver e uma nova possibilidade de agir, mas a adequação e a utilidade dessa nova visão ainda deverá ser descoberta na ação. A reflexão-na-ação envolve, necessariamente, experimento (SCHÖN, 2000).

As atividades apresentadas a seguir ilustram potencialidades da aplicação das tecnologias digitais nas áreas de ensino, pesquisa e extensão, tendo como metodologia as referências aqui descritas.

\section{ENSINO, PESQUISA E EXTENSÃO}

O Departamento de Expressão Gráfica, em colaboração com outros parceiros e instituições, vem realizando disciplinas, pesquisas e ações de extensão com o objetivo de investigar novos métodos projetuais e produção automatizadas (como a PR e FD) no processo de projeto e sua aplicação em diversas áreas de conhecimento, como as artes, a arquitetura, o design, a expressão gráfica e a engenharia. Tais experiências didáticas colaboram para que a formação acadêmica e a construção do conhecimento sejam efetivadas, que promovam o interesse investigativo, contribuam para o processo de ensino-aprendizagem e estimulem a concepção de indivíduos que possuam consciência social e política. Promover essa mediação através do emprego das tecnologias no ensino, na pesquisa e na extensão vem apresentando resultados que comprovam o compromisso de uma educação voltada para a sociedade.

\subsection{Atividades de Ensino}

Nas atividades voltadas para o ensino, nos anos de 2017 e 2018, foram envolvidas seis disciplinas, sendo elas: Tópicos em Computação Gráfica, Tópicos em Desenho de Produtos, Tópicos em Desenho de Robótica, Desenho aplicado ao Design para alunos da Licenciatura em Expressão Gráfica; Desenho de Máquinas e Representação Gráfica para Engenharia voltadas para alunos dos cursos de Engenharia Química e Naval. Totalizando um número próximo a 180 alunos que tiveram a oportunidade de experimentar e entender as tecnologias digitais de prototipagem e a representação tridimensional aplicadas a projetos.

A disciplina Tópicos em Computação Gráfica, apresentou informações sobre as tecnologias de representação 3D interativas, como os motores de jogos Unreal e os softwares de modelagem 3D para tais motores. Já a disciplina Tópicos em Desenho de Produtos, abordou métodos e técnicas de planejamento para realização de protótipos físicos com tecnologias digitais de fabricação. Tópicos em Desenho de Robótica, introduziu conceitos básicos de desenho para sistemas mecânicos e robóticos (Figura 1). Desenho aplicado ao Design (Figura 2), trabalhou desde a criação, desenvolvimento, planejamento, representação gráfica até a execução de um artefato. As disciplinas desenvolvidas para os cursos de engenharia, Desenho de Máquinas (Figuras 3) e Representação Gráfica para Engenharia (Figuras 4), objetivaram o propósito de apresentar métodos de representar e prototipar objetos e sistemas para os cursos específicos. 
Figura 1: Alunos da disciplina de Tópicos em Desenho de Robótica.

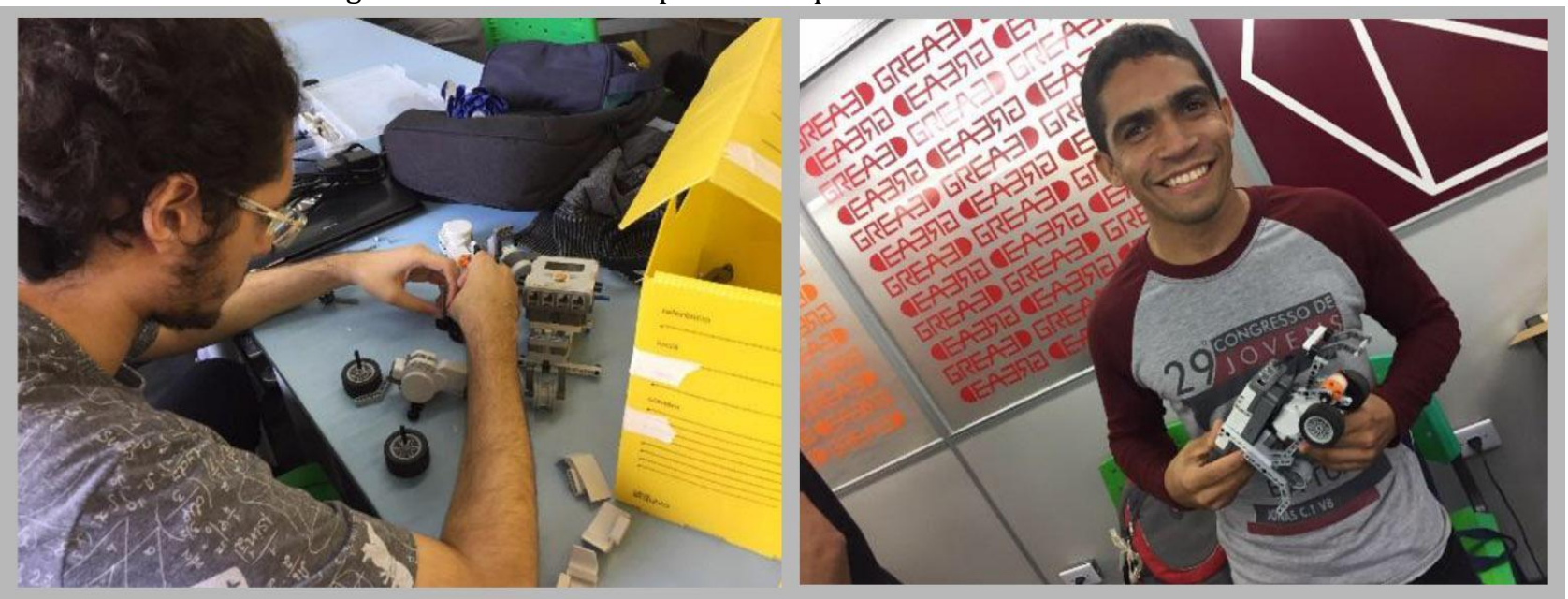

Fonte: Autor (2017).

Figura 2: Modelos de estudos desenvolvidos na disciplina de Desenho aplicado ao Design.

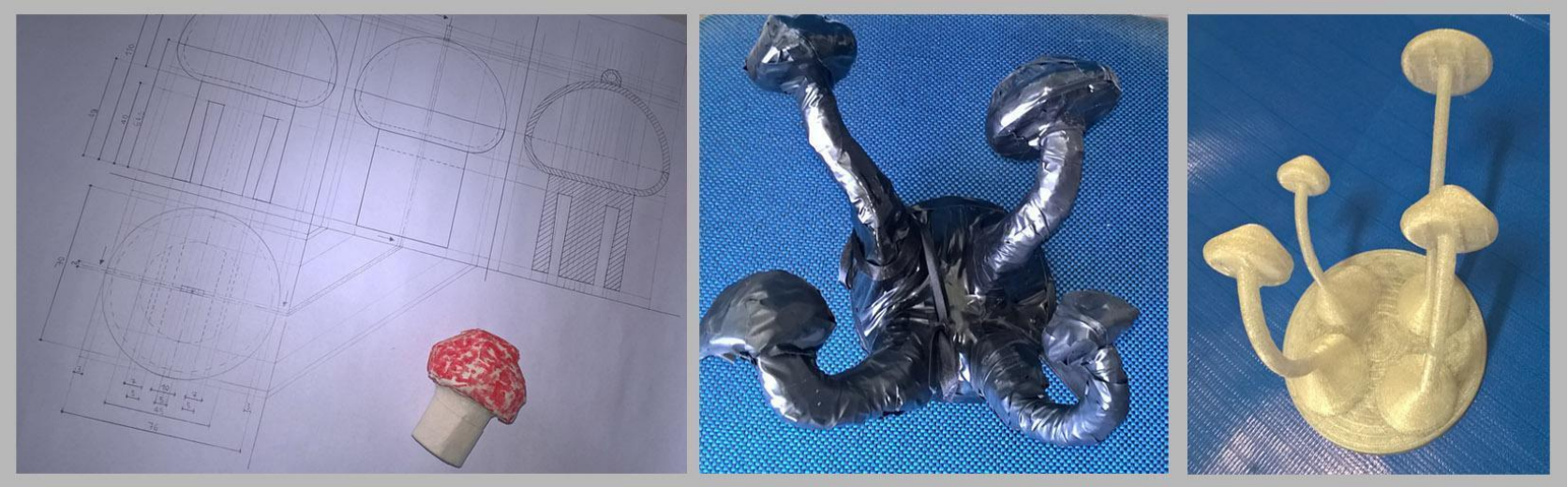

Fonte: Autor (2017).

Figura 3: Braço robótico desenvolvido na disciplina Desenho de Máquinas com utilização de corte a laser.

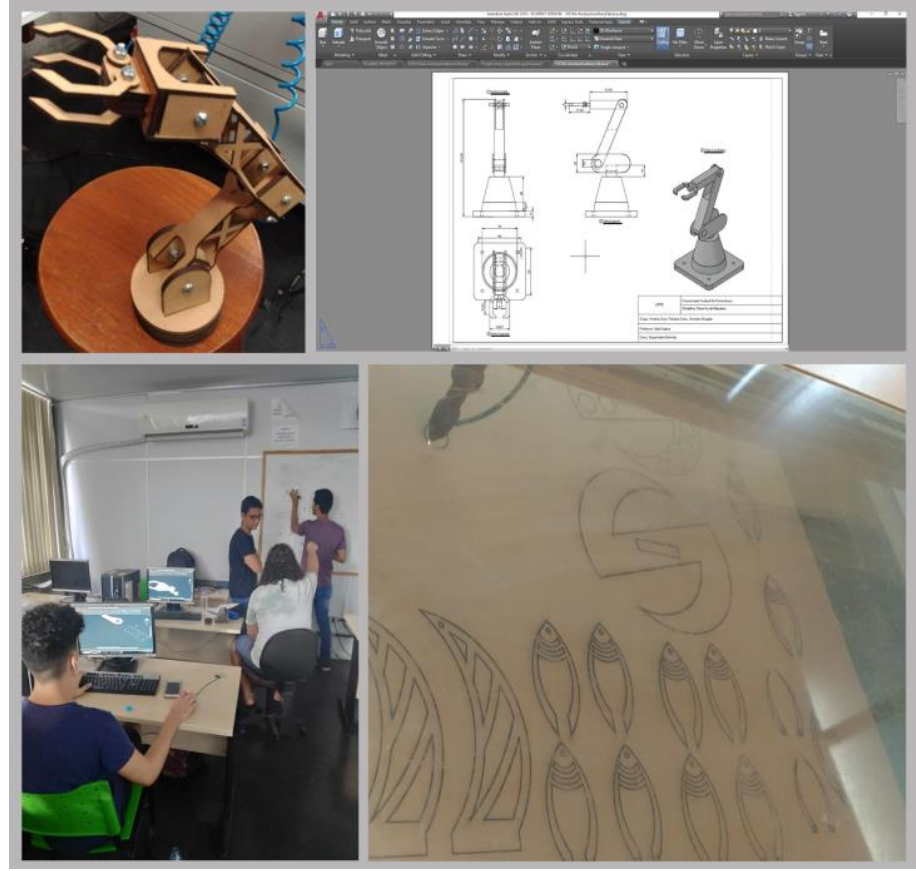

Fonte: Autor (2017). 
Figura 4: Hélice desenvolvida junto aos alunos de Engenharia Naval e modelagem de um barco para a disciplina de Representação para Engenharia.

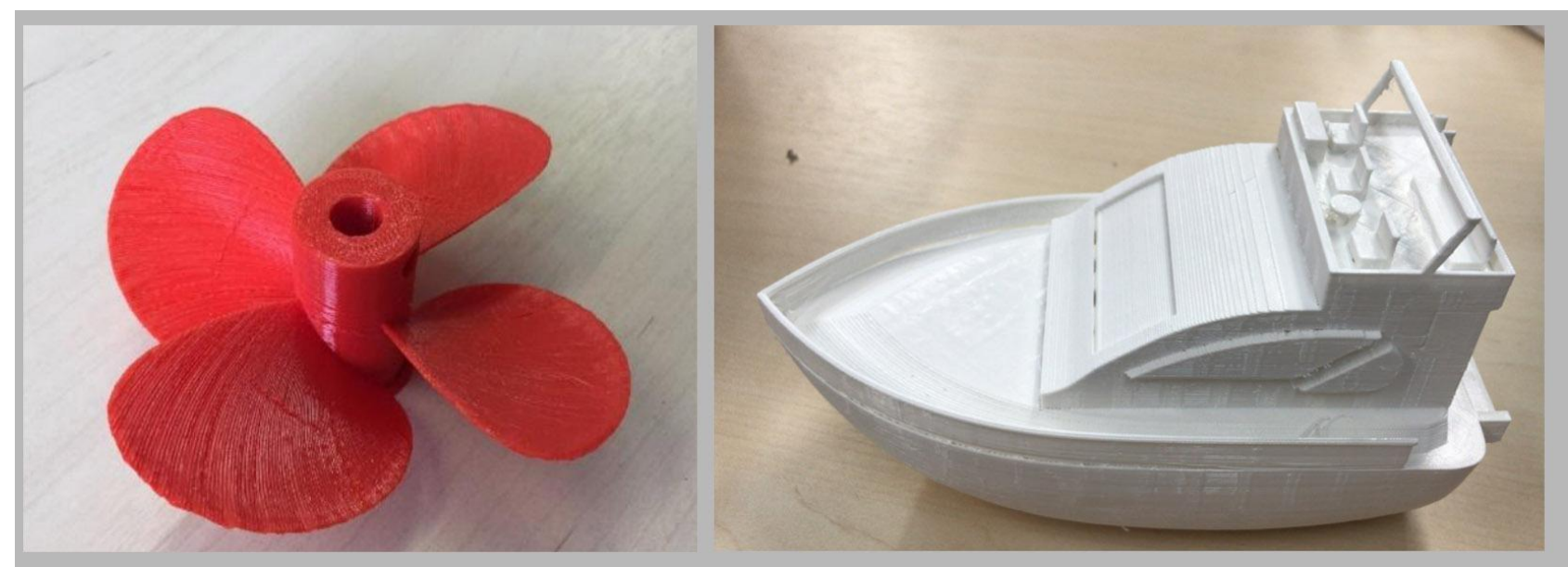

Fonte: Autor (2017).

As imagens apresentadas nas figuras 01 à 04 exemplificam a produção que vem sendo realizada no laboratório GREA3D junto aos alunos no desenvolvimento das disciplinas, possibilitando a melhoria e inovação nas aulas, a aplicação dos conteúdos aprendidos na construção de artefatos, estimulando a utilização de softwares 2D e 3D, além dos equipamentos que facilitam a materialização das ideias.

\subsection{Atividades de Extensão}

\subsubsection{ASSOCIAPE}

Uma das atividades de extensão que vem sendo desenvolvida no laboratório GREA3D desde 2017, é o projeto de extensão 'A arte manual e digital na produção de artefatos artesanais de Pernambuco'. Essa ação tem a parceria com a Associação dos Artesãos de Pernambuco ASSOCIAPE e possibilita a integração entre artesãos, professores e alunos. 0 projeto funciona em formato de oficina prática.

A ASSOCIAPE iniciou suas atividades em março de 1999, a partir da necessidade de um grupo de pessoas, com diversas habilidades manuais, em unir forças para conseguir promover parcerias institucionais e visibilidade no mercado através de apoio para capacitações e da participação em feiras locais, regionais e nacionais. A associação esperava com essa iniciativa fortalecer um grupo de artesãs e artesãos que desejavam, de alguma forma, oficializar o seu trabalho e possibilitar a geração de renda para suas famílias. A ASSOCIAPE agrega mais de quinhentos artesãos e sua abrangência acontece em toda Região Metropolitana do Recife.

Essa proposta de extensão objetiva promover uma experiência prático-pedagógica, envolvendo os alunos e professores da graduação em Expressão Gráfica na construção de moldes e gabaritos tridimensionais que auxiliam a atividade dos artesãos no desenvolvimento dos artefatos executados em tecidos, papel, madeira, entre outros. Este intercâmbio vem sendo implementado através de uma metodologia participativa que agencia a interação entre o saber tradicional da nossa cultura com a aplicação concreta de ferramentas contemporâneas de fabricação digital e prototipagem rápida. 
Os encontros com a equipe da Licenciatura em Expressão Gráfica são realizados uma vez por mês, o laboratório GREA3D disponibiliza um turno, ou seja, quatro horas, onde todos têm acesso a computadores, impressoras 3D e cortadora a laser, além da orientação dos professores que possuem formação em design de produto e arquitetura (Figura 5). Os professores que fazem parte da equipe conhecem e dominam as novas tecnologias empregadas no processo de execução dos moldes e gabaritos, os quais contribuem para melhorias nas peças construídas pelos artesãos junto à equipe acadêmica, como também, trabalham com processo de orientação e desenvolvimento de produtos. Os alunos são treinados e orientados durante todo o período da atividade de extensão.

Figura 5: Equipe de professores com uma dupla de artesãs da ASSOCIAPE durante um encontro no laboratório.
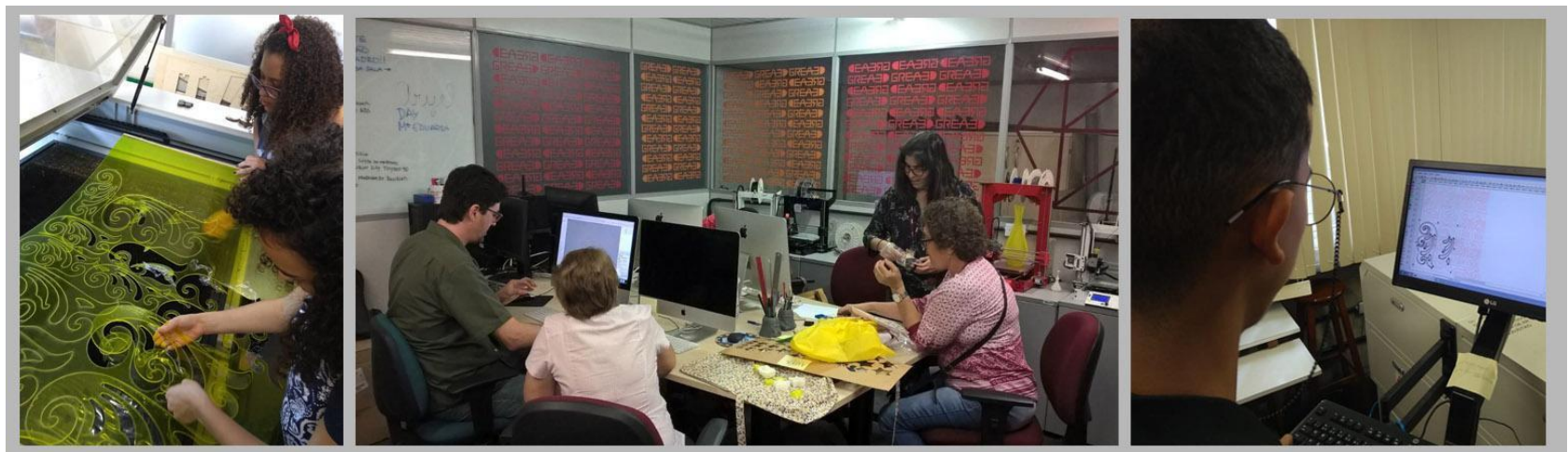

Fonte: Autor (2018)

\subsubsection{Curso de Joias}

Durante o primeiro semestre de 2017 a designer de Joias pernambucana Cris Lemos, da marca CIS Joias, procurou o laboratório GREA3D e apresentou a necessidade de formação específica em Rhinoceros para modelagem e renderização de joias em 3D. A ferramenta de modelagem 3D Rhinoceros está se tornando uma das mais adotadas na área de design de produto por sua versatilidade e precisão. Nas áreas de prototipagem rápida é um software que produz arquivos compatíveis e com os melhores resultados. Na área de Joias é um software largamente utilizado por sua simplicidade de uso em modelagem, rendering e exatidão nas dimensões dos artefatos.

A partir dessa necessidade decidiu-se criar uma parceria, entre o laboratório e a CIS Joias, sob a forma de um curso de extensão que integrasse alunos de graduação e uma profissional da área. Associamos assim o ensino da ferramenta de modelagem com uma experiência prática, através da aplicação em objetos e processos reais de trabalho. 0 curso teve a duração de 20 horas distribuídas em duas semanas e consistiu em métodos e técnicas de modelagem digital NURBS no software Rhinoceros 3D.

Nesse processo, a designer de joias Cris Lemos trouxe exemplos de produtos atuais, onde apresentou problemáticas reais, tanto na etapa de criação quanto na prototipagem das peças, em contrapartida, os alunos puderam contribuir com suas expertises em desenho técnico e geometria; pois, além das problemáticas de concepção e desenvolvimento de uma joia, a artista identificou os tipos de representação gráfica, das imagens e perspectivas, mais utilizadas para expor os produtos para os clientes. 
Os alunos que participaram do curso de joias tiveram acesso às técnicas de modelagens tridimensionais, as tecnologias de impressão $3 \mathrm{D}$ e ao processo metodológico de desenvolvimento de joias. A partir da tecnologia de impressão 3D pode-se construir, por exemplo, protótipos de anéis que serviram para análise e padronização das proporções e dimensões para diferentes tipos de dedos (Figura 6).

A procura pelo curso foi significativa e, ao final, os resultados mostraram que a parceria foi positiva para todos os envolvidos. Ter realizado uma ação de extensão acadêmica, com a parceria de profissionais, enriqueceu o aporte teórico e técnico desenvolvido nos encontros e apresentado aos estudantes da graduação.

Figura 6 - Modelos de joias criados pelos alunos e produzidos em impressora 3D.

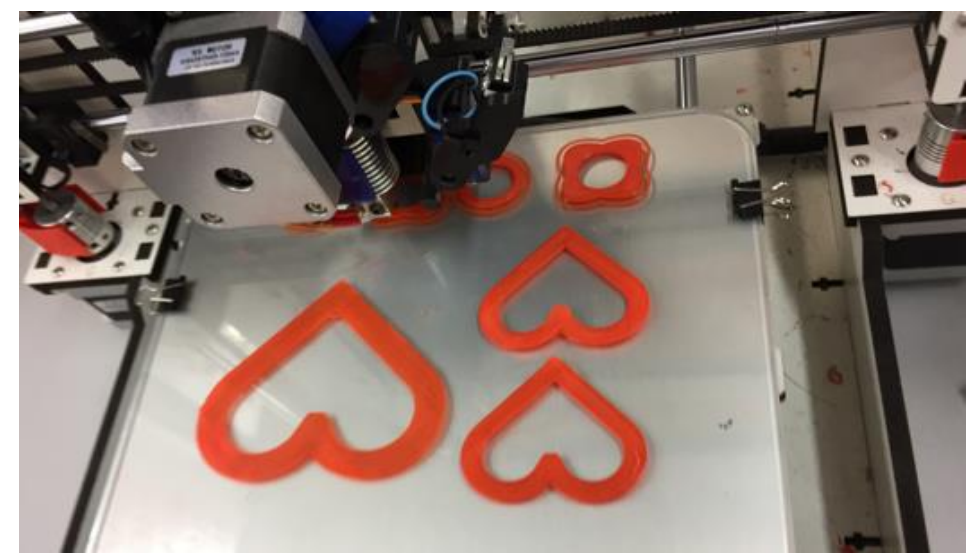

Fonte: Autor (2017).

\subsubsection{Curso de Impressão 3D}

Curso de extensão desenvolvido a partir de métodos de ensino aliados à tecnologia de representação e manufatura digital. 0 curso de impressão 3D teve carga horária de 30 horas e seu principal objetivo foi o de capacitar estudantes, técnicos, professores e pessoas com interesse em tecnologias e desenvolvimento de produtos com a utilização de impressoras 3D, em um contexto de troca de experiência com grupos de diferentes áreas.

A tecnologia utilizada neste curso foi a FDM (Fused Deposition Modeling) que é uma tecnologia aditiva que constrói objetos tridimensionais sobrepondo finas camadas através da extrusão de um material termoplástico. Esta ação de extensão tratou de orientar os interessados em como utilizar as impressoras, compreendendo os seus componentes; manuseio correto e seguro, além da manutenção e calibração das máquinas (Figura 7). Como também, apresentou a utilização de software de planejamento de impressão 3D, que realiza o fatiamento e define diversos parâmetros dos modelos tridimensionais para serem enviados e produzidos por manufatura aditiva.

Com a realização desse curso conseguimos capacitar o público-alvo, pessoas internas e externas a comunidade da UFPE, com interesse em tecnologias e desenvolvimento de produtos a partir do uso da tecnologia FDM, criando assim, uma rede de indivíduos interessados nessas tecnologias contemporâneas. Ao final do curso os participantes 
imprimiram e desenvolveram suas peças, muitas delas estão sendo utilizadas pelo laboratório, como por exemplo: materiais didáticos, ferramentas, suportes, entre outros. Validando, dessa maneira, a experiência que vem contribuindo para uma melhor organização e funcionamento das pesquisas, do laboratório e salas de aula como um todo.

Ainda como atividade final, os estudantes, técnicos e professores elaboraram um tutorial sobre o processo produtivo de cada peça. Esse material traz informações sobre configuração e planejamento aplicados na impressão. Entendemos que o desenvolvimento deste tutorial seja capaz de ajudar outras pessoas que precisam aprender a imprimir utilizando tecnologia 3D. Assim, a conexão criada entre os participantes do curso vem contribuindo para o fortalecimento e divulgação das tecnologias de manufatura aditiva utilizadas em distintas áreas de aplicação.

Figura 7: Integrantes do Curso de Impressão 3D e produção durante a atividade de extensão.

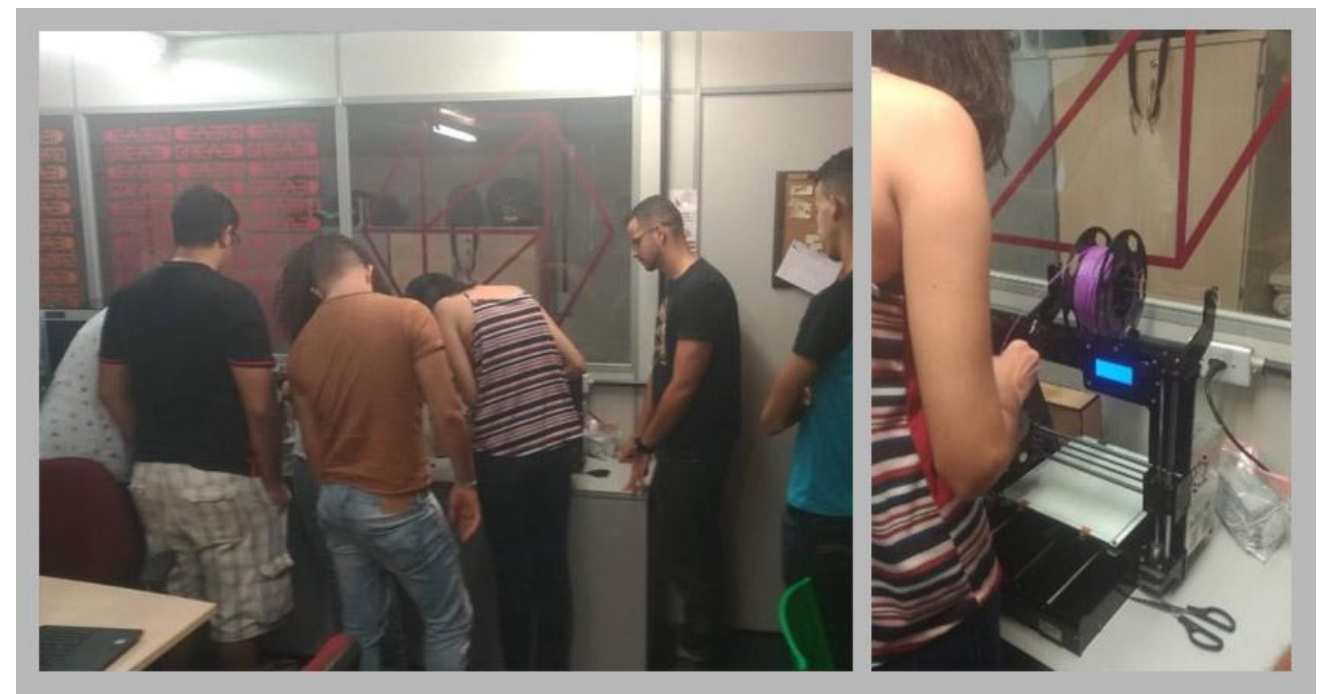

Fonte: Autor (2018).

\subsubsection{Oficina de Luminária com corte a laser}

Este curso foi realizado na 5a Semana da Licenciatura em Expressão Gráfica, evento promovido pelo curso de Licenciatura em Expressão Gráfica da UFPE. A atividade foi destinada para pessoas com interesse na cultura maker, aberta para o público em geral, e teve como objetivo promover os conhecimentos da tecnologia de corte a laser, com a finalidade de apresentar possibilidades de desenvolvimento de projetos para geração de renda, com um baixo custo de investimento.

Na primeira etapa, foi ensinado noções de modelagem 3D em software CAD para a modelagem da Luminária. 0 procedimento é simples, tem-se como ponto de partida a elaboração de um perfil do artefato em formato 2D e, em seguida, utiliza-se o comando de revolução para obtenção da forma 3D. Nesta etapa inicial foram apresentados os componentes que irão compor a luminária, como a lâmpada e o bocal, informações relacionadas às dimensões e destacando a importância do formato escolhido para a luminária para que permita um encaixe preciso e correto na etapa da montagem.

Em seguida, com a forma tridimensional definida o modelo foi exportado para o programa Slicer da Autodesk, este programa é capaz de fatiar modelos 3D virtuais de diferentes 
maneiras e que podem ser reproduzidos em cortadoras a laser. Neste programa, definimos a opção de slicer radial, definimos a quantidade de seções horizontais e verticais, também a espessura do material e a organização do plano de corte (Figura 8).

No terceiro passo desenvolveu-se a produção e a montagem das luminárias. Com o plano de corte, organizado automaticamente pelo programa Slicer, realizamos o corte na cortadora a laser em material, nesse caso utilizamos o papelão pinheiro por ser rígido, denso e vendido em diferentes espessuras. Este software gera uma numeração gravada para auxiliar na montagem das peças e uma animação com o passo a passo da montagem. Após os encaixes, foi realizada a instalação da parte elétrica, fixação do bocal e lâmpada.

A oficina foi realizado para catorze pessoas, teve duração de seis horas e, neste tempo, foram produzidas luminárias com diferentes formas e consequentemente com diferentes efeitos de iluminação. Algumas luminárias do tipo pendente foram expostas na semana do evento e posteriormente cada participante pôde levar sua luminária. Essa atividade despertou no estudante o interesse por novas tecnologias e a possibilidade de criar e produzir um artefato com baixo custo, no caso das luminárias o custo médio foi orçado em $\mathrm{R} \$ 9,00$ reais cada (fio, bocal e papelão pinheiro), e que pode ser comercializado com um bom valor agregado, despertando uma postura empreendedora nos participantes.

Figura 8: Imagens do processo de desenvolvimento, execução e exposição das luminárias produzidas em papelão pinheiro.

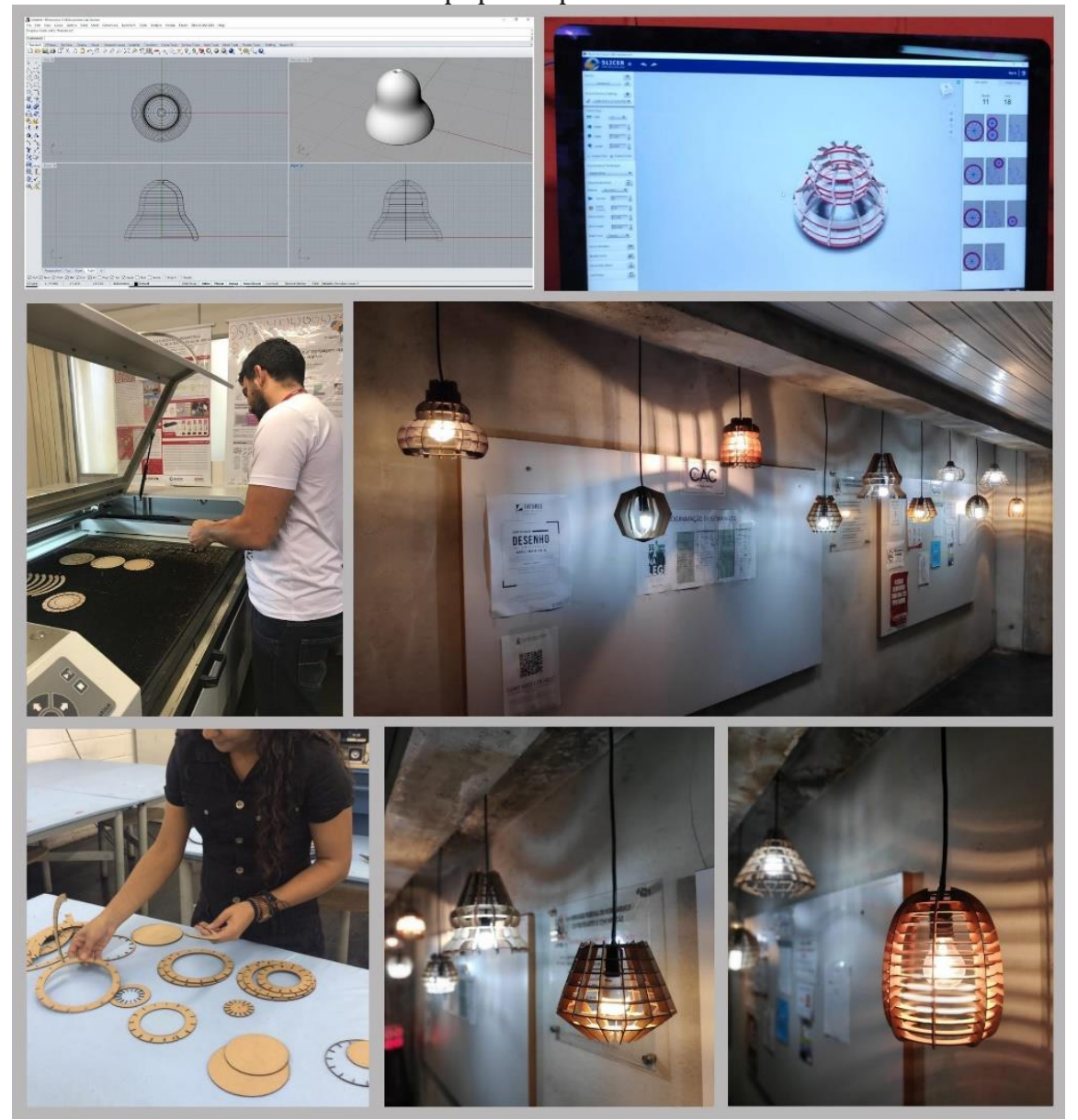

Fonte: Autor (2018). 


\subsubsection{Projeto de Extensão Protótipo Pilar}

Este projeto teve como objetivo envolver alunos de graduação da UFPE e outras instituições de ensino, bem como a Organização não-governamental Instituição Plano B, no desenvolvimento de oficinas artísticas com as crianças e adolescentes da Comunidade do Pilar, localizada no bairro do Recife Antigo - Recife/PE, Brasil.

A Comunidade do Pilar possui o $2^{\circ}$ pior IDH (Índice de Desenvolvimento Humano) da cidade do Recife e acomoda aproximadamente 588 famílias. 0 projeto busca aproximar as crianças e adolescentes - que vivem em condição de vulnerabilidade - das tecnologias de prototipagem rápida, cujo acesso, muitas vezes é restrito à comunidade acadêmica.

As atividades são promovidas em formato de oficinas mensais, envolvendo as tecnologias disponíveis no laboratório GREA3D, como impressão 3D e corte a laser, bem como materiais tradicionais na área de educação artística como: argila, papel, lápis e tintas.

Algumas das oficinas desenvolvidas com as crianças da Comunidade do Pilar tiveram como tema datas festivas como: Natal/2017 - oficina de fôrmas de biscoito utilizando impressão 3D; Dia das Mães/2018 - oficina de cartões (corte a laser) e chaveiros em formato de flor (impressão 3D) para presentear as mães dos participantes e São João/2018 - produção de bandeirinhas cortadas a laser e linha (Figura 9).

Figura 9 - Atividades desenvolvidas com as crianças da Comunidade do Pilar utilizando impressão 3D e materiais cortados a laser.

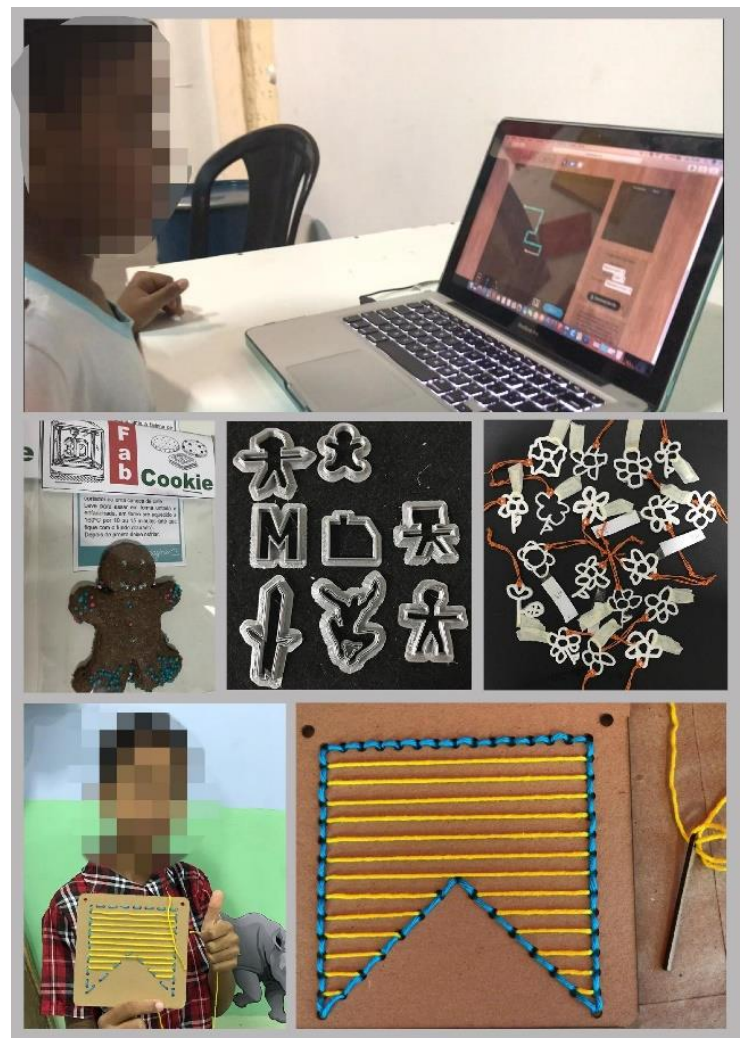

Fonte: Autor (2018). 
Além de incentivar a imaginação e criatividade por meio de atividades de pintura, escultura, modelagem tridimensional/impressão 3D, as atividades buscam contribuir no aprendizado intelectual e criativo, bem como no desenvolvimento da imaginação e capacitação tecnológica por meio de produção artística.

Expomos nessa seção, das Atividades de Extensão, os projetos, cursos e workshop executados no laboratório GREA3D, que permitiram a integração das necessidades de ensino e intervenção social junto às tecnologias disponíveis. 0 papel da Extensão Universitária é promover a associação dos conhecimentos produzidos na academia a partir de uma atitude dialógica com as comunidades e agentes externos à universidade. Nessa perspectiva "com efeito, é graças à extensão que o pedagógico ganha sua dimensão política, porque a formação do universitário pressupõe também uma inserção no social, despertando-o para o entendimento do papel de todo saber na instauração do social" (SEVERINO, 2016).

\subsection{Atividades de Pesquisa}

\subsubsection{Workshop de Modelagem Paramétrica e prototipagem rápida}

Este workshop apresenta uma possibilidade de atualização do ensino de representação a partir da introdução do formalismo denominado Gramática da Forma (STINY e GIPS, 1971) e por meio das ferramentas digitais, em especial, o uso de modelagem paramétrica (MONEDERO, 2000) aliada à prototipagem rápida. Assim, este experimento exemplifica uma atividade de ensino desenvolvida em parceria com o laboratório GREA3D, com o objetivo de contribuir para a introdução de novos métodos de projeto no ensino, bem como no desenvolvimento de novas ferramentas e abordagens projetuais introduzidos na formação profissional.

Este workshop constitui uma das etapas do projeto de pesquisa intitulado $O$ Uso da Modelagem Paramétrica e prototipagem rápida no ensino de Expressão Gráfica e foi realizado em uma disciplina de Geometria Gráfica para o curso de Arquitetura e Urbanismo objetivando ensinar conceitos de desenho geométrico, entendendo que a introdução dessas abordagens pode contribuir para uma compreensão mais interativa dos elementos geométricos e suas propriedades.

O exercício proposto tinha como objetivo o desenvolvimento de cobogós - elemento arquitetônico também conhecido como "elemento vazado" utilizado para melhorar a ventilação e luminosidade em edifícios - a partir do uso do projeto paramétrico (parametric design) e do formalismo denominado Gramática da Forma (em inglês Shape Grammar).

Flório (2011), defende que os conhecimentos de geometria, muitas vezes ministrado de forma isolada - desintegrado das disciplinas "projetuais" da graduação em Arquitetura - são fundamentais para compreender e projetar formas de grande complexidade. Assim, o autor propõe que se "faça uma re-valorização destes conhecimentos diante das facilidades trazidas pelas novas tecnologias de representação e de simulação de espaços".

Nesse contexto, os ambientes de modelagem paramétrica constituem ferramentas ainda pouco exploradas no ensino de geometria. A partir do uso destes softwares, permite-se que o usuário desenvolva modelos por meio de um processo indireto de geração de formas, sendo necessários conhecimentos de programação computacional, matemática e lógica para explorar essas ferramentas no ensino projetual (PEREIRA e VAZ, 2013). 
O workshop foi realizado com a participação de 42 alunos divididos em duplas ou grupos de três estudantes. Na primeira etapa da atividade os alunos foram instruídos na criação de 3 elementos geométricos básicos - círculo, triângulo e quadrilátero no ambiente de programação visual Grasshopper (um plug-in do software de modelagem tridimensional Rhinoceros). Essa atividade requereu conhecimento prévio de conceitos de desenho geométrico, como por exemplo: circuncentro, ortocentro, incentro, raio, diâmetro, além dos vários tipos de triângulos e polígonos com quatro ou mais lados (Figura 10).

Figura 10: Exemplos de implementação no ambiente de programação visual Grasshopper para construção de formas geométricas (A) e construção de triângulos e suas propriedades: circuncentro, ortocentro, incentro (B).

Exemplo de um painel composto por diferentes cobogós gerados por meio de modelagem paramétrica (C).

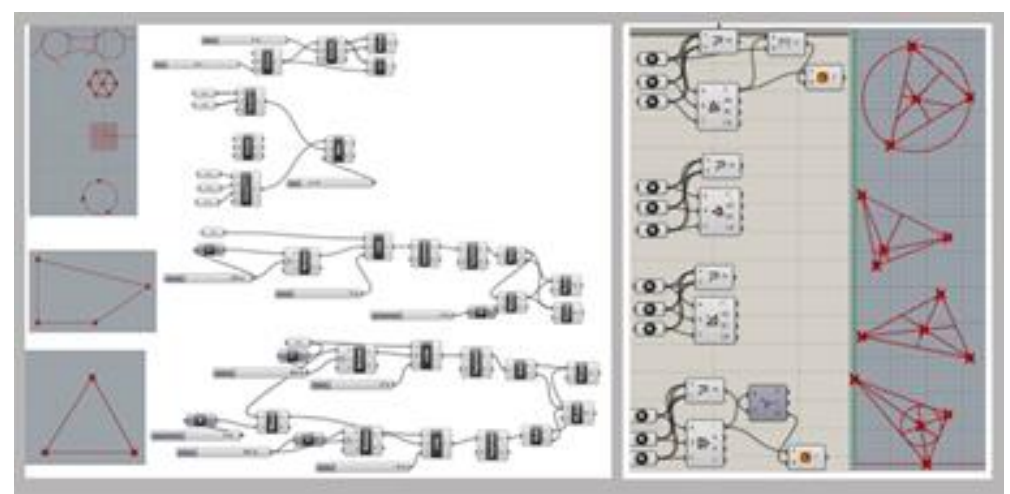

Fonte: Autor (2018).

Como parte dos resultados do experimento, foram gerados modelos físicos dos cobogós, produzidos a partir de uma tecnologia aditiva de prototipagem rápida - Modelagem por Deposição Fundida (em inglês Fused Deposition Modeling - FDM) (Figura 11). Segundo Pallasma (2011), a materialização da forma contribui no desenvolvimento do pensamento projetual e possibilita a comunicação, através do tato, tanto quanto a visão. Dessa forma, o processo de prototipagem permitiu analisar diferentes cobogós pertencentes à uma mesma linguagem, no entanto que apresentavam variações paramétricas. A partir disso, discutiu-se o potencial da utilização de um sistema generativo de projeto (Gramática da Forma associado à modelagem paramétrica) e da prototipagem rápida para customização de produtos.

Figura 11: Processo de impressão 3D (imagem à esquerda) e cobogós produzidos em impressora 3D (imagem à direita).

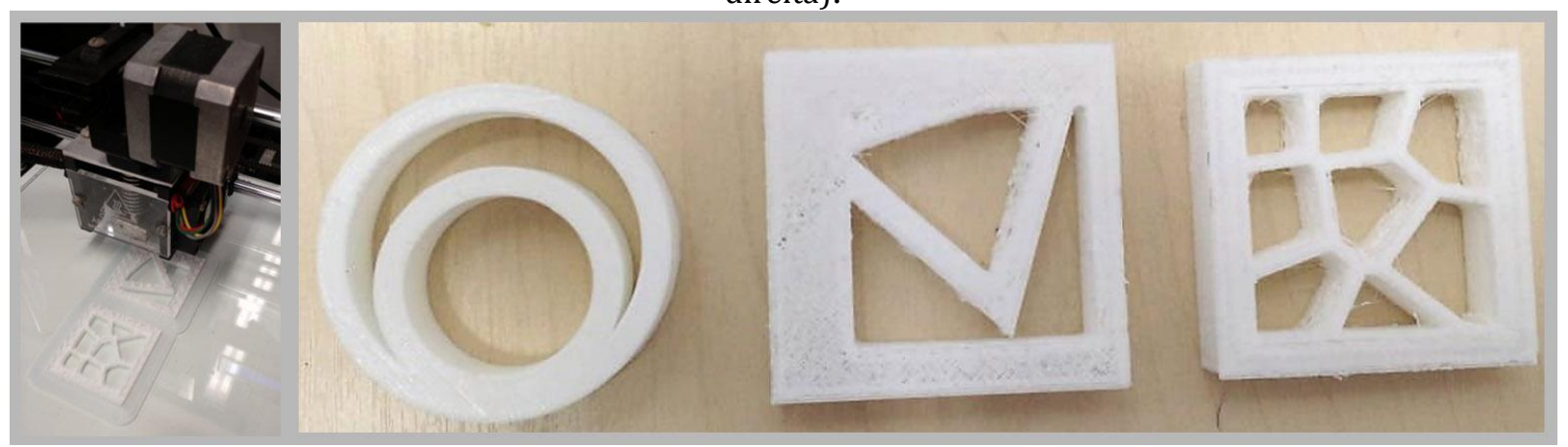

Fonte: Autor (2018). 
O experimento teve como objetivo demonstrar aos participantes que a modelagem paramétrica, ainda que se utilize das tecnologias computacionais, requer conhecimentos de geometria para explorar as potencialidades da ferramenta de maneira consciente e eficiente.

\subsubsection{Personalização de Habitação de Interesse Social no Brasil}

Outra atividade desenvolvida em parceria com o laboratório GREA3D é a pesquisa intitulada "Personalização de Habitação de Interesse Social (HIS) no Brasil", cujo objetivo é analisar técnicas construtivas eficazes, rápidas e de baixo custo aliadas aos conceitos de fabricação digital e prototipagem rápida, buscando contribuir na melhoria da qualidade das moradias, redução de custos e, consequentemente, o aumento da satisfação dos moradores.

De maneira geral, o estudo buscou também explorar métodos construtivos mais eficientes e sustentáveis para ajudar no desenvolvimento de projetos habitacionais, permitindo técnicas mais flexíveis e, possivelmente, mais baratas. 0 estudo explora a possibilidade de criação de projetos de habitação flexível - dentro dos conceitos trabalhados por Till e Schneider (2005) - numa realidade onde o êxito financeiro é comumente priorizado em detrimento da qualidade ambiental.

Para o desenvolvimento de um sistema projetual para personalização de HIS, foi realizado um estudo, por meio do formalismo da gramática da forma, dos projetos vencedores do concurso "Habitação para todos" (CDHU/IAB) (MENDES e CELANI, 2013) em conjunto com a fixação de conceitos referentes a prototipagem rápida e fabricação digital.

Pensando na redução dos custos da construção, acabou optando-se pelo uso de placas cimentícias e do concreto como materiais principais para o fechamento e a estrutura dos conjuntos. 0 módulo base definido foi de $45 \mathrm{~cm}$, de forma que as aberturas geradas atendessem aos padrões de acessibilidade para cadeirantes com facilidade. As funções espaciais, nesse caso, definem as dimensões do ambiente - os cômodos devem atender ao dimensionamento mínimo especificado pela legislação. As peças geradas seguem essa modulação, e permitem diversos tipos de aberturas e passagens (Figura 12).

Figura 12 - Componentes básicos para a montagem das edificações e maquete virtual com exemplo de umas das possíveis soluções.

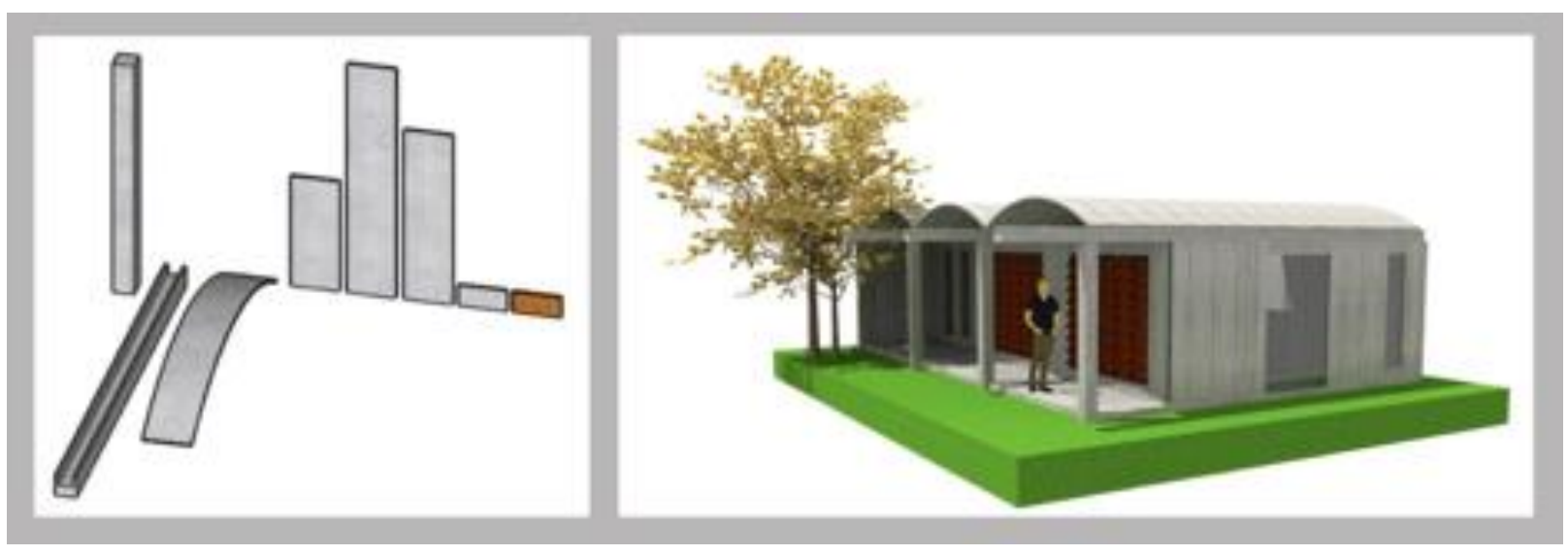

Fonte: Autor (2018). 
O método testado tinha como objetivo facilitar a montagem/desmontagem da unidade habitacional, trabalhando com peças menores, mais leves e que não precisassem de ferragens ou de colas para fixação. A ideia foi trabalhar com blocos de argamassa que fossem encaixados uns nos outros e em pilaretes de formato especial, que serviriam tanto de apoio para a coberta, quanto de peça de ligação para quinas. Isso permitiria que o máximo de peças possíveis fossem transportadas em caso de necessidade.

Após a modelagem, as peças foram impressas em escala (1:10), usando impressora 3D (tecnologia FDM) do laboratório GREA3D, com o intuito de testar encaixes, dimensionamento e viabilidade do sistema construtivo (Figura 13).

Figura 13 - Testes de impressão 3D da peça construtiva desenvolvida em software de modelagem 3D
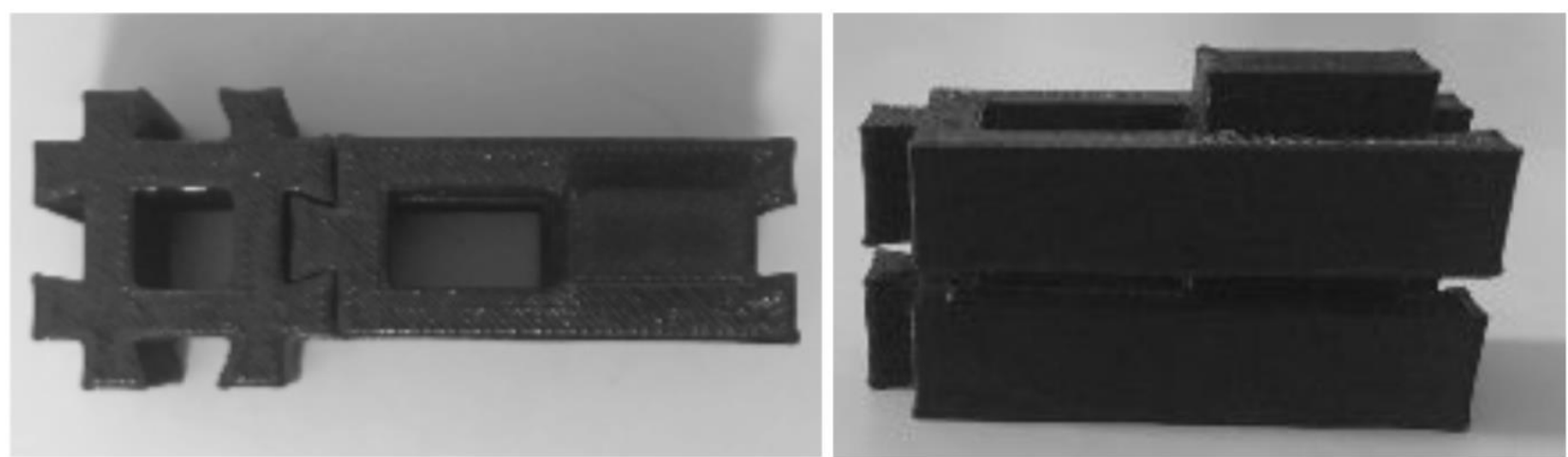

Fonte: Autor (2018).

\section{CONCLUSÕES}

A principal estratégia fundadora do laboratório foi a de articular as ações de ensino, pesquisa e extensão envolvendo alunos voluntários e bolsistas na gestão dos equipamentos de prototipagem rápida e organização dos horários de uso do espaço. Esta estratégia tem se mostrado eficiente e com resultados que satisfazem tanto as exigências de currículo, como também de pesquisa e de ações extensionistas de impacto.

As atividades apresentadas neste artigo, visam ilustrar a diversidade de atuações e parcerias que o laboratório GREA3D tem desenvolvido em pouco mais de um ano de funcionamento. Essas experiências didáticas demonstram o potencial de aplicações das tecnologias digitais em diferentes áreas de conhecimento; destacando, principalmente, sua contribuição na atualização dos conteúdos de geometria ministrados pelo Departamento de Expressão Gráfica e seu impacto em atividades de ensino, pesquisa e extensão.

A atividade de modelagem paramétrica e prototipagem rápida (Figura 11), por exemplo, demonstra a viabilidade de incluir novos conteúdos e atender ao plano de ensino, com os conhecimentos básicos, considerados fundamentais no currículo de geometria. A pesquisa de personalização de HIS busca contribuir na introdução de diferentes abordagens projetuais, da prototipagem rápida e fabricação digital no desenvolvimento de diversidade de tipologias habitacionais (Figura 12). E, por sua vez, o projeto de extensão na Comunidade do Pilar (Figura 9) apresenta uma possibilidade de promover o conhecimento multidisciplinar entre os alunos da UFPE, a ONG Instituição Plano B e as crianças da comunidade por meio das tecnologias 
digitais, demonstrando a importância das ações extensionistas na aquisição e troca de conhecimentos. Os projetos, aulas e cursos realizados no laboratório são apresentados e discutidos pelos coordenadores para verificação de viabilidade. Além disso, os professores envolvidos sugerem suas ações, parcerias e metodologias que serão utilizadas na implementação das atividades junto ao laboratório.

Dessa forma, o presente artigo apresentou exemplos de atuação de um laboratório de prototipagem rápida frente aos desafios de integrar pensamento criativo e crítico no currículo de geometria, da gestão de um espaço multidisciplinar e do debate da introdução de procedimentos que conciliam as novas tecnologias com os processos artesanais e do conhecimento digital com o saber tradicional.

\section{AGRADECIMENTOS}

0 presente trabalho foi realizado com o apoio da FACEPE - Fundação de Amparo à Ciência e Tecnologia de Pernambuco - (Processo APQ no 0781-6.04/15), da ProExC/PROACAD e do Programa de Bolsa de Iniciação Científica UFPE/CNPq (por meio das bolsas concedidas aos alunos Júlia Lins e Silva Dutra, Aline Vieira e Yuri da Silva Martins de Macedo). Os autores também gostariam de agradecer a importante contribuição da equipe de monitores voluntários (Gabriel Varela, Polyana Tarquínio, Igor Xavier, João Carvalho, Antônio da Silva Neto, Beatriz Brandão, Davi Batista Bezerra, Mario Ruiz Manrique, Sarah Diniz de Sousa, Túlio Seabra da Silva e Yaírla Guedes Alves) à parceria com a ONG Instituição Plano B, aos professores, artesãos e parceiros que colaboraram com a realização das experiências apresentadas nesse artigo, por saberem compartilhar os seus conhecimentos, à deputada Luciana Santos pela emenda parlamentar para aquisição de equipamentos para o laboratório Grea3D.

\section{REFERÊNCIAS BIBLIOGRÁFICAS}

[1] ORTEGA, L. (2009). (Ed.) La digitalización toma el mando. Barcelona: Editorial Gustavo Gili.

[2] PUPO, R.; CELANI, G.(2008). Implementando a fabricação digital e a prototipagem rápida em cursos de arquitetura: dificuldades e realidades. Cuba: Congreso de La Sociedad Iberoamericano.

[3] PUPO, R.; CELANI, G. (2011). A Prototipagem Rápida e a Fabricação Digital: um novo desafio para o ensino de arquitetura. Campinas.

[4] PUPO, R., DUARTE, J. e CELANI, G. (2008). Introducing digital fabrication into the architectural curriculum: two similar experiences in different contexts. Congresso ECAADE. Antwerpen. 
[5] TRIPP, D. (2005). Pesquisa-ação: uma introdução metodológica. Trad. Lólio Lourenço de Oliveira. Educação e Pesquisa, São Paulo, v. 31, n. 3, p. 443-466.

[6] LEWIN, K. (1946). Action research and minority problems. Journal of Social Issues, n. 2, p. 34-36.

[7] SCHÖN, D. (1983). The reflective practitioner: how professionals think in action. Nova York: Basic Books, 1983.

[8] SCHÖN, D.A. (2000). Educando o Profissional Reflexivo: um novo design para o ensino e a aprendizagem. Trad.Roberto Cataldo Costa. Porto Alegre: Artmed.

[9] STINY, G.; GIPS, J. (1971). Shape Grammars and the Generative Specification of Painting and Sculpture, in C V Freiman (ed) Proceedings of IFIP Congress 71 (Amsterdam: North-Holland). Republished in O R Petrocelli (ed), The Best Computer Papers of 1971 (Philadelphia: Auerbach) pp125-13.

[10] MONEDERO, J. Parametric design - a review and some experiences. Automation in Construction, 9, 2000, 369-377.

[11] FLÓRIO, W. (2011). Modelagem Paramétrica, Criatividade e Projeto: duas experiências com estudantes de arquitetura. In: Gestão e Tecnologia de Projetos. Vol. 6, N. 2, São Carlos, p. 43-66.

[12] PEREIRA, N. S., VAZ, C. V. (2013). Parametrismo e Ensino de Geometria - As Superfícies de Felix Candela. Disponível em: <http://wright.ava.ufsc.br/ grupohipermidia/graphica2013/trabalhos/PARAMETRISMO\%2 0E\%20ENSINO\%20DE\%20GEOMETRIA\%20AS\%20SUPERFICIES\%20DE\%20FELIX\%20CAN DELA.pdf.>

[13] PALLASMA, J. (2011) As Mãos Inteligentes: A sabedoria Existencial e Corporalizada na Arquitetura. Porto Alegre: Bookman.

[14] TERZIDIS, K. (2006). Algorithmic Architecture. Burlington: Elsevier. 
[15] SEVERINO, Antônio Joaquim. Metodologia do trabalho científico. 24ạ ed. São Paulo: Cortez, 2016.

[16] TILL, J., SCHNEIDER, T. Flexible housing: the means to the end. Architectural Research Quarterly (Online), v. 9, n. 3-4. p. 287-296. Setembro 2005.

[17] MENDES, L.T., CELANI, G. (2013). O uso da Gramática da Forma para análise de conjuntos habitacionais de interesse social no Brasil: O concurso "Habitação para Todos". Congresso Internacional de Habitação no Espaço Lusófono. CIHEL - LNEC, Lisboa, 193-194. 